\title{
Chronic Kidney Disease specific cardiovascular risk factors among non dialytic patients with Chronic Kidney Disease stage-V-An experience of a specialized hospital
}

\author{
Saha $\mathrm{M}^{1}$, Faroque $\mathrm{MO}^{2}$, Alam $\mathrm{KS}^{1}$, Alam $\mathrm{MM}^{1}$, Ahmed $\mathrm{S}^{1}$ \\ ${ }^{I}$ Department of Nephrology, National Institute of kidney Diseases \& Urology, Dhaka, ${ }^{2}$ Department of \\ Nephrology, Bangabandhu Sheikh Mujib Medical University,Dhaka,Email:m_saha09@yahoo.com
}

\begin{abstract}
The study was carried out to see prevalence of Chronic Kidney Disease (CKD) specific cardiovascular risk factors and cardiovascular events among patients with Chronic Kidney Disease stage-V (CKD-V) before starting dialysis therapy in the department of Nephrology of National Institute of Kidney Diseases \& Urology (NIKDU), Dhaka, Bangladesh. Among CKD specific cardiovascular risk factors, anemia showed the highest prevalence $(96.7 \%)$ in study population. More than fifty percent of CKD-V patients had both hypocalcaemia and hyperphosphataemia. Calcium-Phosphate Product (CaXP) was elevated among 23 percent of the population. C-reactive protein, an acute phase protein was positive in $78 \%$ of CKD-V patients. Besides, among traditional risk factors, Hypertension and Diabetes Mellitus were present in $83.3 \%$ and $23 \%$ of the study population respectively. The prevalence of cardiovascular events among CKD-V patients showed that $18.3 \%$ had ischemic heart disease, $38 \%$ heart failure, $4.7 \%$ arrhythmia and $9 \%$ left ventricular hypertrophy. Females were significantly prone to develop cardiovascular events than their male counterpart $(\mathrm{p}=0.028)$. Diabetes was significantly higher in patients with cardiovascular complications than in patients without cardiovascular complications $(\mathrm{p}=0.021)$.
\end{abstract}

\section{Introduction}

Chronic Kidney Disease (CKD) is a global problem equally affecting the people of developed countries as well as developing countries. Cardiovascular disease is by far the leading cause of morbidity and mortality in CKD patients, accounting for almost $40 \%$ of hospitalizations ${ }^{1}$ and almost $50 \%$ of deaths $^{1,2}$. After stratification for age, race and gender, the cardiovascular mortality rate in End Stage Renal Disease (ESRD) patients is 10-20 times that in the general population ${ }^{3}$. At the time of starting renal replacement therapy, prevalence of cardiovascular disease among Chronic Kidney Disease $(\mathrm{CKD})$ patients is high ${ }^{1,4,5}$. The prospective Canadian study had reported an incidence of approximately $10 \%$ per year for both ischemic heart disease and cardiac failure in incident patients, significantly greater than values seen in general population ${ }^{6}$. In Hemo study, the most common cause of death in dialyzed patient was ischemic heart diseases $(20.4 \%)$ followed by cardiac rhythm disorder $(10.4 \%)^{7}$. The results of a number of studies suggest that factors leading to the development of cardiovascular abnormalities begin to operate very early in the progression of CKD, well before the patients reach $\mathrm{ESRD}^{8}$.
In a community-based cohort, it was found that the prevalence of all the major traditional cardiovascular risk factors other than smoking (including hypertension, diabetes, hypercholesterolaemia and overweight) was significantly higher in patients with even mild renal failure (serum creatinine $>1.5 \mathrm{mg} / \mathrm{dl}$ ) than in those with normal renal function, suggesting that they are associated even with the earliest stages of $\mathrm{CKD}^{9}$. A series of CKD specific risk factors can further increase a patient's cardiovascular risk from the earliest stages of the disease ${ }^{2}$.

In Bangladesh approximately 100-120 Patients per Million Population (PMP) reach End Stage Renal Disease (ESRD) every year ${ }^{10}$. The incidence of $\mathrm{CKD}$ is increasing rapidly. At the same time cardiovascular risk factors and events increase the fatal outcome of CKD patients. Many of the CKD$\mathrm{V}$ patients can not start or continue dialysis because of cardiovascular diseases. Besides, cardiovascular events are the leading causes of mortality among dialysis patients. This is extremely important as it has been widely shown that the cardiovascular status at the beginning of dialysis greatly affects patient outcomes ${ }^{5}$. There is no study done before in Bangladesh to see the prevalence of CKD specific 
cardiovascular risk factors among Non-dialytic patients with CKD-V. But such base line information about cardiovascular factors before starting dialysis among CKD-V patients is essential to develop effective preventive and control strategy for the prevention of cardiovascular events in CKD patients. This study was done to observe CKD specific cardiovascular risk factors and cardiovascular events among patients with $\mathrm{CKD}-\mathrm{V}$ before initiation of dialysis in a tertiary label hospital of Bangladesh.

\section{Materials and Methods}

This study was carried out on CKD-V patients before initiation of dialysis therapy in nephrology department of National Institute Kidney Diseases \& Urology for one year period from July, 2008 to June, 2009. At first, CKD-V patients were selected randomly according to inclusion criteria, then relevant history was taken and physical examination was carried out after taking permission of subjects. Relevant investigations were done. Initially there were 316 patients, later on 16 patients were dropped out due to lack of availability of all investigations. Data were analyzed to find out etiology of CKD and prevalence of cardiovascular risk factors with events with the help of computer software SPSS (Statistical Package for Social Sciences), version 11.5.

\section{Inclusion Criteria:}

1. Age above 18 years

2. Patients with CKD-V [Estimated Glomerular Filtration Rate (eGFR) $<15 \mathrm{ml} / \mathrm{min} / 1.73 \mathrm{~m}^{2} \geq 3$ months] before starting dialysis therapy

\section{Exclusion Criteria:}

1. Age below 18 years

2. Patients with CKD-V who had already started haemodialysis

Operational definitions:

CKD specific Cardiovascular risk factors: Anemia, C-reactive protein, $\mathrm{S} \mathrm{Ca}^{++}, \mathrm{S}_{\mathrm{PO}_{4}}^{-}$and $\mathrm{Ca} \mathrm{X} \mathrm{P}$ product

Traditional Cardiovascular risk factors: Hypertension, Diabetes Mellitus, Age, Sex, Obesity or Overweight, Smoking, Dyslipidaemia,

Cardiovascular Events: We have seen the following cardiovascular events Ischemic Heart Disease (IHD), Arrhythmia, Left ventricular hypertrophy (LVH), Congestive Heart Failure (CCF). As Echocardiogram is not available in this institute, we included clinical, ECG and Radiological criteria to define cardiac events.
$C K D-V$ :

According to Kidney Disease Outcome Quality Initiative (KDOQI) guidelines Patients with eGFR $<15 \mathrm{ml} / \mathrm{min} / 1.73 \mathrm{~m}^{2} \geq 3$ months was considered as $\mathrm{CKD}-\mathrm{V}^{11}$. Estimated Glomerular filtration rate (eGFR) was estimated from serum creatinine level by using Modification of Diet in Renal Disease (MDRD) prediction equation.

The MDRD equation:

$\operatorname{GFR}\left(\mathrm{ml} / \mathrm{min} / 1.73 \mathrm{~m}^{2}\right)=186 \mathrm{X}(\mathrm{Scr})^{-1.154} \mathrm{X}(\text { Age })^{-0.203}$ $\mathrm{X}(0.742$ if female)

Anaemia: When $\mathrm{Hb} \%<11 \mathrm{gm} / \mathrm{dl}$ in premenopausal women and when $\mathrm{Hb} \%<12 \mathrm{gm} / \mathrm{dl}$ in men and post menopausal women ${ }^{11}$.

Ischemic Heart Disease (IHD): To define Ischemic Heart Disease we had included known cases of Ischemic Heart Disease or new cases of Ischemic Heart Disease ${ }^{3}$.

Arrhythmia: Atrial or ventricular rhythm disorder requiring therapy ${ }^{3}$.

Cardiac Failure: Persistent or recurrent dyspnea plus two of the followings: Raised jugular venous pressure, bibasilar crackles, pulmonary venous hypertension or interstitial edema on chest X-ray ${ }^{12}$.

Left Ventricular Hypertrophy (LVH): individuals needed to meet voltage criteria and had either the $\mathrm{S}-\mathrm{T}$ segment characteristics or $\mathrm{T}$ wave characteristics.

R-wave amplitude $\geq 25 \mathrm{~mm}$ in any deflection in precordial leads

R-wave amplitude $\geq 20 \mathrm{~mm}$ in standard Leads

R-wave amplitude $\geq 11 \mathrm{~mm}$ in augmented unipolar leads

R-wave amplitude in V5 or V6 plus $\mathrm{S}$ amplitude in $\mathrm{V} 1$ or $\mathrm{V} 2 \geq 35 \mathrm{~mm}$

S-T segment characteristics "Depressed S-T segments"

$\mathrm{T}$ wave characteristics "Flattened to inverted $\mathrm{T}$ waves" 13,14

\section{Results}

Among study population, $22.7 \%$ was below 30 years of age, $19.3 \%$ between $30-40$ years, $17 \%$ between $40-50$ years, $19.3 \%$ between $50-60$ years and $21.7 \% 60$ years or above. The mean age of the patients was $43.5 \pm 15.3$ years; the lowest and highest ages were 14 and 80 years respectively. Fifty eight percent of the patients were male and the rest (42\%) was female, giving a male to female ratio of roughly 3:2 respectively. About $41 \%$ of patients were urban resident and the rest $59.7 \%$ rural residents. Majority $(93.3 \%)$ of the patients was Muslim, $6.4 \%$ was Hindu and $0.3 \%$ was belonged to other religion. Over two-third (68\%) patients had Glomerulonephritis, 21.3\% Diabetes, $2 \%$ Hypertension and $8.7 \%$ other causes. 
Anemia showed the highest prevalence (96.7\%) among CKD specific factors. More then fifty Percent of study population had hypocalcaemia and hyperphosphataemia. CaXP Product was elevated among 23 percent of the population. Seventy eight percent of ESRD patients were positive for Creactive protein, an acute Phase protein (Table-I).

Among traditional risk factors, $83.3 \%$ had Hypertension and 23\% had Diabetes mellitus. Regarding Dyslipidaemia, 46.6\% had raised LDL cholesterol and $57.3 \%$ had raised Triglyceride level. Of them, $27 \%$ had habit of smoking where as $20 \%$ was suffering from overweight and obesity.

Data on prevalence of cardiovascular events among CKD-V patients showed that $18.3 \%$ had ischemic heart disease, $38 \%$ heart failure, $4.7 \%$ arrhythmia and $9 \%$ left ventricular hypertrophy. Half of the patients did not have any cardiovascular events, about one-third (32.3\%) had single event, $15 \%$ two events and $2.7 \%$ had three events.

Females with CKD were significantly prone to develop cardiovascular events like IHD, heart failure, arrhythmia or LVH than their male counterpart $(\mathrm{p}=0.048)$. But age was not found to have significant association with cardiovascular events $(\mathrm{p}=0.080)$.

Smoking habit and body mass index were almost identically distributed between groups $(\mathrm{p}=0.897$ and $\mathrm{p}=0.564$ respectively). The prevalence of Anaemia and Hypertension had no significant difference $(\mathrm{p}=0.185$ and $\mathrm{p}=0.535$ respectively) between groups. Diabetes was significantly higher in patients with cardiovascular complications than those patients without cardiovascular complications $(\mathrm{p}=0.021)$ (Table-II).

None of the CKD Specific factors had any significant difference between subjects who developed cardiovascular events and subjects who did not develop cardiovascular events $(p>0.05$ in each case) (Table-III).

Table I. Distribution of patients by CKD Specific risk factors $(n=300)$

\begin{tabular}{lcc}
\hline Specific factors related to CKD & Frequency & Percentage \\
\hline Anaemia & 290 & 96.7 \\
Hypocalcaemia $(<8.1 \mathrm{mg} / \mathrm{dl})$ & 172 & 57.3 \\
Hyperphosphatemia $(>5.5 \mathrm{mg} / \mathrm{dl})$ & 165 & 55 \\
Product of calcium and phosphate & 69 & 23 \\
$\left(>55 \mathrm{mg}^{2} / \mathrm{dl}^{2}\right)$ & & \\
C-reactive protein & 234 & 78 \\
\hline
\end{tabular}

Table II: Association between Traditional Risk factors and CV events $(n=300)$.

\begin{tabular}{lccc}
\hline Traditional Risk factors & \multicolumn{2}{c}{ Cardiovascular events } & p-value \\
\cline { 2 - 3 } & $\begin{array}{c}\text { Developed } \\
(\mathrm{n}=150)\end{array}$ & $\begin{array}{c}\text { Not developed } \\
(\mathrm{n}=150)\end{array}$ & \\
\hline Smoking habit & $40(26.7)$ & $41(27.3)$ & 0.897 \\
$\begin{array}{l}\text { Smoker } \\
\text { Non-smoker }\end{array}$ & $110(73.3)$ & $109(72.7)$ & \\
BMI (Nutritional status) & & & \\
Under weight \& normal & $118(78.7)$ & $122(81.3)$ & 0.564 \\
Overweight \& obese & $32(21.3)$ & $28(18.7)$ & \\
Anaemia $(<12$ g/dl $)$ & & & \\
Present & $146(97.3)$ & $144(96.0)$ & 0.185 \\
Absent & $4(2.7)$ & $6(4.0)$ & \\
$\begin{array}{l}\text { Hypertension } \\
\text { Present }\end{array}$ & $127(84.7)$ & $123(82.0)$ & 0.535 \\
Absent & $23(15.3)$ & $27(18.0)$ & \\
$\begin{array}{l}\text { Diabetes mellitus } \\
\text { Present }\end{array}$ & $44(29.3)$ & $27(18.0)$ & 0.021 \\
absent & $106(70.7)$ & $123(82.0)$ & \\
\hline Chisquar $\left(\chi^{2}\right)$ Test was & & \\
\hline
\end{tabular}

\# Chi square $\left(\chi^{2}\right)$ Test was employed to analyze the data;

Figures in the parenthesis denote corresponding percentage.

Table III: Association between CKD Specific factors and CV events $(n=300)$

\begin{tabular}{lccc}
\hline Specific factors related to CKD & \multicolumn{2}{c}{ CV events } & p-value \\
\cline { 2 - 3 } & $\begin{array}{c}\text { Developed } \\
(\mathrm{n}=150)\end{array}$ & $\begin{array}{c}\text { Not } \\
\text { developed } \\
(\mathrm{n}=150)\end{array}$ & \\
\hline Raised LDL $(>100 \mathrm{mg} / \mathrm{dl})$ & $65(43.3)$ & $72(48.0)$ & 0.417 \\
TG $(>150 \mathrm{mg} / \mathrm{dl})$ & $89(59.3)$ & $83(55.3)$ & 0.484 \\
Low HDL $(<40 \mathrm{mg} / \mathrm{dl})$ & $117(78.0)$ & $128(85.3)$ & 0.101 \\
Hypocalcaemia $(<8.1 \mathrm{mg} / \mathrm{dl})$ & $81(54.0)$ & $91(60.7)$ & 0.243 \\
Hyperphosphatemia $(>5.5 \mathrm{mg} / \mathrm{dl})$ & $78(52.0)$ & $87(58.0)$ & 0.296 \\
Product of calcium and phosphate & $34(22.7)$ & $35(23.3)$ & 0.891 \\
(> 55 mg $\left.{ }^{2} / \mathrm{dl}^{2}\right)$ & & & \\
C-reactive protein $($ Positive) & $120(80.0)$ & $114(76.0)$ & 0.347 \\
\hline
\end{tabular}

Data were analyzed using Chi-square $\left(\chi^{2}\right)$ Test.

Figures in the parentheses denote corresponding percentage.

\section{Discussion}

This was the hospital based study on CKD-V patients to see the prevalence of CKD Specific cardiovascular risk factors and events before starting of dialysis therapy.

There are several cardiovascular risk factors which are specific for CKD. Anaemia, Hypocalcaemia, Hyperphosphataemia, Calcium-Phosphate product, inflammatory proteins like $\mathrm{C}$ - reactive protein and Homocystinaemia are those specific factors responsible for cardiovascular disease in Chronic Kidney Disease patients. Anaemia, which is thought to make a substantial contribution to the development of cardiac abnormalities in CKD patients, is a very frequent complication. Anaemia is itself responsible for Left Ventricular Hypertrophy which is the hallmark of cardiovascular events. A number of observational studies have shown that it inversely correlates with residual renal function, yet its prevalence is already high during the earlier stages of $\mathrm{CKD}^{15-17}$. 
Astor BC et al found in a large-scale study of haemodialysis patients, higher hyperphosphataemia levels were significantly associated with an increased risk of death, even after adjusting for preexisting medical conditions, the delivered dialysis dose, estimates of nutritional status and estimates of non-compliance ${ }^{18}$. These results, which have been confirmed and even extended by another study $^{19}$, clearly demonstrate that hyperphosphataemia directly contributes to the excessive mortality of CKD patients, in whom it recently has been defined as a 'silent killer' ${ }^{, 20}$. The exact mechanisms by which hyperphosphataemia leads to increased mortality have not yet been completely clarified, but they probably involve the calcification (due to increased calcium-phosphate product and/or secondary hyperparathyroidism) of coronary plaques, cardiac valves and myocardial tissue $^{21}$. According to our study, anaemia was found to be most prevalent $(96.7 \%)$ among CKD specific risk factors. Hypocalcaemia $(57.3 \%)$ and hyperphosphataemia (55\%) also showed higher distribution in study population. CaXP Product was elevated among 23 percent of the population.

Now a day it is established that high serum concentrations of markers of systemic inflammation (including C-reactive protein and interleukin-6) have been associated with atherosclerosis $^{22,23}$ and increased cardiovascular mortality in ESRD patients ${ }^{24-26}$. In our study $80 \%$ of $\mathrm{CKD}-\mathrm{V}$ patients were positive for C-reactive protein. This high inflammatory protein clearly indicates that most of CKD-V patients are in great risk of developing atherosclerosis and cardiovascular diseases.

Hypertension, Diabetes mellitus, Smoking, Dyslipidaemia and old age are the established risk factors for developing cardiovascular disease in CKD patients. Locatelli et al found that age, gender, smoking, previous cardiovascular disease, hypertension, diabetes and total serum cholesterol were all significantly increased $(\mathrm{P}<0.001)$ in patients with an estimated creatinine clearance of $\leq 60 \mathrm{ml} / \mathrm{min}^{27}$. In our study, among traditional risk factors, more than 50 percent patients had Hypertension, high LDL cholesterol and high Triglyceride where as prevalence of Diabetes, habit of Smoking and Obesity was less than 30 percent. As a whole all the major risk factors that we had seen in our study, were present in significant number among study population.

A large scale study from western countries conducted by Foley RN and his colleagues revealed that clinical manifestations of cardiovascular disease were highly prevalent at the start of ESRD therapy: $14 \%$ had coronary artery disease, $19 \%$ angina pectoris, $31 \%$ cardiac failure, $7 \%$ dysarrhythmia and $8 \%$ peripheral vascular disease. On echocardiography $15 \%$ had systolic dysfunction, $32 \%$ left ventricular dilatation and $74 \%$ left ventricular hypertrophy. The overall median survival time was 50 months ${ }^{4}$.

In our study, we found that $18.3 \%$ had ischemic heart disease, $38 \%$ heart failure, $4.7 \%$ arrhythmia and $9 \%$ left ventricular hypertrophy. Although, LVH is very frequent among CKD patients, in our study, prevalence of left ventricular hypertrophy was underestimated because only ECG criteria was used for detection of LVH. The Canadian MultiCenter Study of Renal Anemia in patients with various stages of CKD found that the prevalence of LVH progressively increased with declining renal function from the $30 \%$ prevalence at an early CKD stage (creatinine clearance $50-75 \mathrm{ml} / \mathrm{min})^{28}$.

When we tried to elicit association between cardiovascular risk factors and cardiovascular events, we found that age had no significant association with cardiovascular events $(\mathrm{p}=0.080)$. Females were significantly prone to develop cardiovascular events than their male counterpart $(p=0.048)$. Diabetes was significantly higher in patients with cardiovascular complications than that in patients without cardiovascular complications $(\mathrm{p}=0.021)$.But it was seen that Anemia, Hypertension, Smoking and Obesity had no significant relationship to develop cardiovascular events. In addition, none of the CKD specific risk factors were significantly associated with cardiovascular complications.

The prevalence of both cardiovascular risk factors and events was high in our study but it was failed to find out significant association between most of the cardiovascular risk factors and cardiovascular events among CKD-V patients before starting dialysis therapy because most of our study population was below fifty years and major cause of CKD of our study population was glomerulonephritis.

Conclusion: Cardiovascular diseases are the leading cause of morbidity and mortality among CKD patients. The result of this study suggests that both cardiovascular risk factors and events are prevalent among patients with CKD-V. Female sex and Diabetes Mellitus are significantly associated with cardiovascular events in same group of patients. A large scale study is essential for detection and management of CKD specific cardiovascular risk factors in the early stages of Chronic Kidney Disease to prevent and halt the morbidity and mortality of CKD patients. 


\section{Acknowledgement}

This study was funded by HNPSP, Govt. of Bangladesh through BMRC, Bangladesh.

\section{References}

1. US Renal Data System. 2002 Annual Data Report, The National Institutes of Health, National Institute of Diabetes and Digestive and Kidney Diseases, Bethesda, MD; 2002.

2. Locatelli F, Marcelli D, Conte F et al. Cardiovascular disease in chronic renal failure: the challenge continues. Nephrol Dial Transplant 2000; 15 [Suppl 5]: 69-80.

3. Foley RN, Parfrey PS, Sarnak MJ. Clinical epidemiology of cardiovascular disease in chronic renal disease. Am J Kidney Dis 1998; 32 [Suppl 3]: S112-S119.

4. Foley RN, Parfrey PS, Harnett JD. Clinical and echocardiographic disease in patients starting end-stage renal disease therapy. Kidney Int 1995; 47: 186-192.

5. Locatelli F, Marcelli D, Conte F. Patient selection affects end-stage renal disease outcome comparisons. Kidney Int 2000; 57 [Suppl 74]: S94-S99.

6. Churchill DN, Taylor DW, Cook RJ, Laplante P, Barre P, Cartier P, Fay WP, Goldstein MB, Jindal K, Mandin H, McKenzie JK, Muirhead N, Parfrey PS, Posen GA: Canadian haemodialysis morbidity study. Am $\mathrm{J}$ of Kidney Dis 1992;19 (3), 214-234.

7. Rocco MV, Yang G, Gassman J, Lewis JB, Ornt D,weiss B and Levey AS: Comparison of causes of death using Hemostudy and HCFA end stage renal diseases death notification classification systems. The national institute of health funded Haemodialysis, Health care Financing Administration. Am J of Kidney Dis 2002; 39(1), 146-153.

8. Ruilope LM, Vanveldhuisen DJ, Ritz E and Luschen TT 2201. Renal function: The Cinderella of cardiovascular risk profile. J Am Coll Cardiol 2001: 38 (7), 1782-1787.

9. Culleton BF, Larson MG, Wilson PW, Evans JC, Parfrey PS, Levy D. Cardiovascular disease and mortality in a community based cohort with mild renal insufficiency. Kidney Int 1999; 56: 2214-2219.

10. Rashid HU. Bangladesh Renal Registry Report (19861996). Bangladesh renal J 2002; 21(1): 25-28.

11. National Kidney Foundation. KDOQI Kidney Disease Outcome Quality Initiative Am J Kidney Dis.2002; 39:S1-S266.

12. Parfrey PS, Harnetf 3D, Griffith SM, Gault MH, Barre $\mathrm{P}$ : Congestive heart failure in dialysis patients. Arch Mt Med 1988 (17) 148:1519-1525.

13. Weiner DE, Tighiouart H, Vlagopoulos PT, Griffith JL, Salem DN, Levey AS \& Sarnak MJ :Effect of Anaemia \& Left Ventricular Hypertrophy on Cardiovascular Disease in Patient with Chronic Kidney Disease. J Am Soc Nephrol 2005; 16: 241-247.
14. Kannel WB, Feinleib M, McNamara PM, Garrison RJ, Castelli WP: An investigation of coronary heart disease in families. The $\mathrm{F}$ framingham offspring study. Am J Epidemiol 1979; 110: 281-290.

15. Obrador GT, Ruthazer R, Arora P, Kausz AT, Pereira BJ. Prevalence of and factors associated with suboptimal care before initiation of dialysis in the United States. J Am Soc Nephrol 1999; 10: 17931800.

16. Pisoni RL, Port FK, Bragg JL et al. Anaemia management practices in Europe: results from DOPPS [abstract]. Nephrol Dial Transplant 2002; 17 [Suppl 1]: $23 \mathrm{~A}$.

17. Levin A, Thompson CR, Ethier J et al. Left ventricular mass index increase in early renal disease: impact of decline in hemoglobin. Am J Kidney Dis 1999; 34: 125-134.

18. Astor BC, Muntner P, Levin A, Eustace JA, Coresh J. Association of kidney function with anemia: the Third National Health and Nutrition Examination Survey (1988-1994). Arch Intern Med 2002; 162: 1401-1408.

19. Block GA, Hulbert-Shearon TE, Levin NW, Port FK.Association of serum phosphorus and calcium phosphate product with mortality risk in chronic hemodialysis patients: a national study. Am J Kidney Dis 1998; 31: 607-617.

20. Levin NW, Hulbert-Shearon TE, Strawderman RL. Which causes of death are related to hyperphosphataemia in hemodialysis (HD) patients? J Am Soc Nephrol 1998; 9: 217A.

21. Amann K, Gross ML, London GM, Ritz E. Hyperphosphataemia-a silent killer of patients with renal failure? Nephrol Dial Transplant 1999; 14: 2085-2087.

22. Stenvinkel P, Heimburger O, Paultre F et al. Strong associations between malnutrition, inflammation and atherosclerosis in chronic renal failure. Kidney Int 1999; 55:1899-1911.

23. Zoccali C, Benedetto FA, Mallamaci $\mathrm{F}$ et al. Inflammation is associated with carotid atherosclerosis in dialysis patients. J Hypertens 2000; 18: 1207-1213

24. Yeun JY, Levine RA, Mantadilok V, Kaysen GA. Creactive protein predicts all-cause and cardiovascular mortality in hemodialysis patients. Am J Kidney Dis 2000; 35: 469-476.

25. Zimmermann J, Herrlinger S, Pruy A, Metzger T, Wanner C. Inflammation enhances cardiovascular risk and mortality in hemodialysis patients. Kidney Int 1999; 55: 648-658.

26. Stenvinkel P. Inflammation in end-stage renal failure: could it be treated? Nephrol Dial Transplant 2002; 17 [Suppl 8]: S33-S38.

27. Locatelli F, Del Vecchio L, Pozzoni P. The importance of early detection of chronic kidney disease. Nephrol Dial Transplant 2002; 17 [Suppl 11]: 2-7.

28. Levin A, Thompson CR, Ethier $\mathbf{J}$ et al. Left ventricular mass index increase in early renal disease: impact of decline in hemoglobin. Am J Kidney Dis 1999; 34: 125-134. 